\title{
The Role of Sophisticated Accounting System in Strategy Management
}

\author{
David Naranjo-Gil. Pablo de Olavide University at Sevilla. Spain \\ dnargil@dee.upo.es
}

\begin{abstract}
Organizations are designing more sophisticated accounting information systems to meet the strategic goals and enhance their performance. This study examines the effect of accounting information system design on the performance of organizations pursuing different strategic priorities. The alignment between sophisticated accounting information systems and organizational strategy is analyzed. The enabling effect of the accounting information system on performance is also examined. Relationships are explored using data collected from $112 \mathrm{CEO}$ in 218 hospitals in Spain. The findings provide support of an indirect effect of sophisticated accounting information system on performance, acting through a prospector strategy.
\end{abstract}

Keywords: Accounting information system, strategy, performance, contingency theory.

\section{INTRODUCTION}

Strategy literature provides evidence that organizations develop several types of strategies in order to improve their performance (Miles and Snow, 1978; Porter, 1985). However, they do not always get the intended performance. Recently, accounting literature argues that strategic success is considered an outcome of Accounting Information System's² (AIS) design (Langfield-Smith, 1997). Several

\footnotetext{
1 This study has been partially funded by the Spanish Ministry of Science and Technologies (project PB-981358) and Andalucía Government (project SEJ-111). My thanks to Paolo Perego, Marcel Van Rinsum, Victor Maars and two anonymous reviewers for helpful comments.

2 Others authors have used the term Management Information System (MIS) and Management Accounting System (MAS) to name the same construct of AIS (e.g. Abernethy and Guthrie, 1994; Bouwens and Abernethy, 2000). In this paper the term AIS refers to a system embracing and providing a broader scope of information (not only financial information) to decision makers within the organization (Chenhall, 2003).
} 
studies have analyzed the role of AIS in strategic management, examining the attributes of AIS under different strategic priorities (Ittner and Larcker, 1997; Bouwens and Abernethy, 2000). It has also been analyzed the effect on performance of the interaction between certain types of strategies and different design of AIS (e.g. different techniques and information). Empirical results thus far are mixed (Langfield-Smith, 1997; Chapman, 1997). Research on the relationship between strategy and AIS has usually focused on one single attribute at a time. More seldom, AIS have been looked upon as a system. The present study attempts to provide some clarification of the relationship between AIS design, organizational strategy and performance, by explicitly addressing the information content of AIS design. We examine the AIS as a system rather than focus on specific characteristics or techniques of the AIS. Our basic assertion is that the appropriate design of AIS supports business strategies in ways that increase to organizational performance (Chenhall, 2003).

This study uses a contingency-based approach, which has been extensively applied to both strategic research and accounting information research (Donaldson, 2001; Chenhall, 2003). Moreover, the contingency approach is the only one which asserts that organizational performance depends on the existence of a fit between the characteristics of an organization and the situation in which it operates (Lawrence and Lorsch, 1967; Donaldson, 2001). The empirical study is undertaken in the public hospitals sector in Spain, where the introduction of competition provides an opportunity to gauge how different strategies and AIS designs detracted from firm performance or enhanced it. Data were collected from 218 Chief Executive Officers (CEOs) of public hospitals using a mail questionnaire. A satisfactory response rate was achieved with 112 useful questionnaires returned (51.37\%).

This paper attempts to contribute to the accounting information literature in several ways. First, this research provides robust evidence on how the AIS design relates to strategy. Second the present study provides evidence in favor of the contingency approach, through a more integral explanation of the eventual contingency fit between AIS and strategy by an explicit consideration of several forms of fit (Gerdin and Greve, 2004). Finally, while prior research suggests that the AIS design enables strategy, the present study directly tests the presence of this relationship and examines a performance outcome of the enabling effect.

The remainder of this paper is structured as follows. Section 2 reviews the relevant literatures and develops hypotheses about the relationship between AIS, 
strategy and performance. Section 3 describes the design of the empirical survey study. Section 4 presents the results from the statistical analyses of the hypotheses. Finally, section 5 presents the discussion and conclusions of this study, provides the limitations of the current study, and points out some directions for further research.

\section{THEORETICAL DEVELOPMENT AND HYPOTHESES FORMULATION}

There is a large body of research into accounting information systems using the contingency approach (Chenhall, 2003; Chapman, 1997). Basically this approach asserted that there is no universally appropriate AIS that can be applied to every situation since the effectiveness and usefulness of AIS are contingent on (depends on) certain external factors (e.g. market and environment) and internal factors (e.g. technology and strategy). In this vein, Otley (1980) suggested that contingencybased research in accounting has to demonstrate an appropriate fit between specific aspects of AIS and organizational circumstances. However, the meaning of fitness is ambiguous (Donaldson, 2001). Different methods analyzing fitness express different interpretations of it (Drazin and Van de Ven, 1985; Venkatraman, 1989). The concept of fit can be defined as the degree to which the needs, objectives and/or structure of one component are consistent with the needs, objectives and/or structure of another component (Donaldson, 2001). Bergeron, Raymond and Rivard (2001) studied the impact of information technology on business performance and they concluded that significant differences exist in the findings in every perspective of fit analyzed. In the present study it is assumed that the organizational performance is a function of the strategy and the AIS. Fitness will exist in the combination of strategy and AIS that contribute to performance. The mediating and moderating effect of AIS in the relationship between strategy and performance are analyzed (Hartman and Moers, 1999; Gerdin and Greve, 2004).

\subsection{Accounting information system and strategy}

Strategy has been examined using different typologies, such as Porter (1985) or Miles and Snow (1978). The latter has been extensively used in management literature (Zajac and Pearce, 1990). The typology of Miles and Snow (1978) focused on the interaction organization-environment and the rate of change in products or markets. It distinguished four organizations based on their strategic 
pattern: Defenders, Prospectors, Analyzers and Reactors. The typology of Miles and Snow (1978) has been frequently examined along the continuum of defenders and prospectors, since analyzers are a hybrid of defenders and prospectors, and reactors have no strategy (Kald, Nilsson and Rapp, 2000). Organizations adopting a defender strategy focus on process efficiency by providing standard, high volume products with low margins for which costs of service and innovation are minimal. The ultimate objective is to maintain market areas and niches, competing with products with high quality and low cost. In contrast, organizations adopting a prospector strategy often focus on providing a product or service based on the consumer's perception of features, functionality, uniqueness, and responsiveness. This lead to look for new products and markets, instead of cost competition.

In contingency research the relationship between strategy and AIS has been extensively analyzed in a passive way, suggesting that AIS are one of the consequences of strategy (Langfield-Smith, 1997). Recently several studies have asserted that AIS play a proactive role in the strategy management, acting as a mechanism that enables organizational strategy (see Chenhall, 2003; Gerdin and Greve, 2004). In this vein, Galbraith (1977) asserted that an organization can be viewed as an information processing mechanism, which enables the particular strategy chosen by the firm. Fiegener (1994) also argued that AIS can play an active role in strategy management, through maintaining the dynamic alignment of strategies, ensuring that they remain effective over time and integrating the strategies throughout the organization into tactical plans.

The AIS design can be defined in terms of the information characteristics that it provides (Chenhall and Morris, 1986; Gul, 1991). Chenhall and Morris (1986) described AIS according to the perceived usefulness of four information attributes, namely scope, timeliness, level of aggregation, and integration. Scope refers to the measures being used and to the extension of AIS in time and space. Then information could focus on future vs. historical events or external vs. internal events. Also the information could be quantified in monetary or non-monetary terms. Timeliness refers to the frequency, speed of reporting and the orientation of the information (e.g. short or long run). Aggregation refers to the way data is aggregated in time periods, functions or in accordance with decision models. Finally, integration refers to the need of providing information to reflect the interaction and coordination effects of several functions in the organization. These four attributes have been analyzed for comparing AIS and organizational strategies 
(Gerdin and Greve, 2004). Extending the Chenhall and Morris'(1986) study, Gul (1991) combined the four information characteristics to describe accounting system in terms of AIS Sophistication, which addresses a range of information available for managers, rather than perceived as useful (Gul, 1991; Gul and Chua, 1994). Gul (1991) adopted the view that AIS may be conceptualized in terms of a continuum from low sophisticated (traditional) AIS to high sophisticated AIS. A high sophisticated AIS design provides information which has a high average level in the four characteristics. That is, it provides information which is broad scope, high coordinated, external oriented and integrated among different organizational functions (Bouwens and Abernethy, 2000). Firms with a more risky strategy, such as prospectors, would be more inclined to use broader accounting information, in order to scan the environment and meet the market demands (Miles and Snow, 1978; Abernethy and Guthrie, 1994). Abernethy and Guthrie (1994) found a positive interaction effect between prospectors and broad scope AIS. Bouwens and Abernethy (2000) asserted that to manage decentralization and flexibility, such as prospector strategy, managers would require sophisticated AIS information to cope with the uncertainty and optimize the decision making (Gul, 1991). In this vein, Gordon and Miller (1976) asserted that organizations operating in uncertain environments more than other organizations will need a high load of information, both quantitative and non-quantitative, for facilitating the strategic decision making. There are some empirical results that support this assumption. Ittner and Larcker (1997) found empirical evidence for the relationship between quality strategy and the increased use of non-financial information. Similar results were found by Perera, Harrison and Poole (1997) in organizations following a customer-oriented strategy. Gul (1991) found that broad scope information (both financial and non-financial) which is external to the organization is essential for evaluating competitive actions. Also, timely and frequent information is useful, since managers need to respond rapidly to changes in the competitive environment (Gul, 1991, p. 88). Gul (1991) argued that the use of sophisticated AIS under conditions of low change and the information overload may be dysfunctional for organizational objectives. In this vein, Johnson and Kaplan (1987) argued that traditional or less sophisticated AIS provide information very suitable for managing routine, regular and programmable activities, which are characteristics of organizations pursuing a defensive strategy. Therefore, we formulate the following hypothesis

H1: There is a positive relationship between more sophisticated AIS and more prospector strategy. 


\subsection{The relationship between AIS, strategy and performance}

Contingency-based research has assumed extensively that if certain structures were more common than others in a given situation, these structures would also lead to higher performance (Donaldson, 2001). However, the signaling survival of the fit is too crude a proxy for performance, even more in public sector organizations (Donaldson, 2001). Then, contingency-based research in accounting agrees that fitness must be demonstrated by measuring performance (see Chenhall, 2003). The focus of most prior studies has been either on documenting the performance effects of the information systems or in finding the factors affecting the success of the information systems (Barua, Kriebel and Mukhopoadhyay, 1995; Brown and Magill, 1994). Only recently have studies begun to examine whether organizations systematically vary the AIS design to support their chosen strategy, recognizing that AIS have the potential to facilitate strategy management and enhance organizational performance (see Gerdin and Greve, 2004). For example, Abernethy and Guthrie (1994) found that the differences in organizations' strategies tend to affect the scope of their information systems. They found that organizations pursuing a differentiation strategy are more effective using broad scope AIS. This included a high load of information, such as internal/external, financial/non-financial and past/future oriented. Abernethy and Guthrie (1994) also found that organizations fitting a cost strategy to narrow scope AIS are the most effective. However, this type of AIS is not appropriate for enhancing the performance of organizations pursuing a customization and flexibility strategy (Ittner et al., 1997; Bouwens and Abernethy, 2000). Gul (1991) concluded that sophisticated AIS contribute to performance in high perceived environmental uncertainty situation, which involves highly competitive actions and market demand. Gul (1991) also found that sophisticated AIS hamper performance under low perceived environmental uncertainty situation (Gul, 1991, p. 88). If AIS can be linked to strategy and strategy is linked to performance, then we can argue that sophisticated AIS can be expected to have positive effects on performance through a strategy focused on flexibility and change, such as prospectors. However, contingency research (see Gerdin and Greve, 2004) suggests that the interaction between strategy and AIS affects to performance. Thus, the relationship between prospector strategy and performance would be moderated by the sophisticated design of AIS. According to the previous argument we analyze the contingency fit between AIS, strategy and performance, using a mediating (H2) and moderating (H3) model. Therefore, we formulate the following hypotheses: 
H2: There is a positive indirect relation between sophisticated AIS and organizational performance acting through prospector strategy.

H3: The interaction of sophisticated AIS and prospector strategy will improve organizational performance.

\section{EMPIRICAL STUDY}

Data were collected through a questionnaire from CEOs in the 218 public hospitals in Spain. We selected this setting for several reasons. First, Public Hospital sector has been the object of some recent studies exploring organizational and strategic roles of accounting information systems (Abernethy and Brownell, 1999; Abernethy and Vagnoni, 2004). Second, we focus on a single sector for reducing the noise in our measures and controlling of variables of no theoretical interest. Third, the health care industry, not only in Spain but also in Europe, is undergoing fundamental shifts in thinking and operating that demand transformation into an effective new health care system (Carretero, 2000; Errasti, 1997). Hospitals have been increasingly required over recent years to be more responsive towards customers' demands while at the same time improving quality, flexibility and efficiency (Carretero, 2000). Spanish authorities encourage public hospitals to adapt their accounting information systems in order to control cost service and increase the flexibility and quality, being the ultimate objective to enhance the hospital efficiency and effectiveness. This reason assured that the issues central to this study were considered to be relevant for the population, with positive expected consequences for the willingness to cooperate. The CEOs data was obtained through Spanish National Catalogue of Hospitals, updated through internet and telephone calls. A satisfactory response rate was achieved with 112 useful questionnaires returned $(51.37 \%)$.

\subsection{Measurement of variables}

Sophisticated AIS Design was measured by a modified version of the scale developed by Chenhall and Morris (1986). Following Gul (1991) and Gul and Chia (1994), we developed an instrument to measure the available accounting information, rather the perceived usefulness of different aspects of accounting information (Chenhall and Morris, 1986). We asked questions regarding to the four dimensions identified by Chenhall and Morris (1986): Scope, Timeliness, Aggregation and Integration. CEOs had to state the extent which they perceive 
that their hospital's AIS provide each of the dimensions identified. Following Gul (1991) we treat all information characteristics as complementary to construct the variable sophistication of AIS design by averaging the scores for all items. The Cronbach alpha for the overall scale was $0.73^{3}$, exceeding the recommended minimum level (Nunnally, 1978).

Organizational strategy was measured based on Miles and Snow's (1978) typology of strategy. Following the studies by Snow and Hrebiniak (1980) and Shortell and Zajac (1990) the instrument asks which of two descriptions (defender and prospector organizations) best describes the hospital. In addition, following Golden (1992) and Abernethy and Brownell (1999), the respondents were also asked to place strategy types along a five-point scaled anchored from " 1 " (defender) to " 5 " (prospector). This allows the organizational strategy to be represented as continuous variable. High scores of the scale indicate a prospective strategy and low scores indicate a defender strategy. The appendix contains an overview of the questionnaire.

Organizational performance was measured using published hospital output, since the use of CEO's self-rating has been criticized if researchers can access to objective data (Pedhazur and Pedhazur, 1991). Following Van Peursem, Pratt and Lawrence (1995) we used data of Hospital Performance Measures published by the Health Care Regional Services. Hospital performance measurements indicate the use of health resources in four key hospital areas: Hospitalization, Surgery, Emergency and Outpatient Service (Errasti, 1997). In every key area we chose one indicator based on 18 interviews among top managers in 4 Spanish public hospitals. The organizational performance was constructed by averaging the scores of the following four indicators: (1) use of hospital beds, (2) use of surgery rooms, (3) pressure of emergency, and (4) external readmission rate. Every Spanish public hospital reported these indicators to the Health Care Regional Services, which are validated in order to publish comparable performance measurement among hospitals ${ }^{4}$. Table 1 shows the four indicators used for constructing the organizational performance.

\footnotetext{
3 In this study we assumed that all four information dimensions load on the construct equally (Gul, 1991). We did not perform a previous factor and Cronbach analyses for every dimension, since the construct was created by averaging all information characteristics.

4 Hospitals in different regions can use different labels for the same performance indicators. For example Hospitals in Andalucía used "Successive Admissions Rate" instead of "Readmission rate". In every hospital the four performance rates are calculated with similar and comparable data.
} 


\begin{tabular}{|l|c|}
\hline Hospitalization Area: Use of Hospital beds & $\frac{\text { Stays in bed }}{\text { Beds in hospitals }}$ \\
\hline Surgery Area: Use of Surgery rooms & $\frac{\text { Surgical operations }}{\text { Number of surgery rooms }}$ \\
\hline Emergency Area: Pressure of Emergency & $\frac{\text { Inpatients through emergency }}{\text { Total inpatients }}$ \\
\hline Outpatient Service Area: External Readmission rate & $\frac{\text { Second or more outpatient visit }}{\text { Total of outpatient visit }}$ \\
\hline
\end{tabular}

Table 1: Organizational Performance

This study controlled the potential effect of two variables over the relationship hypothesized: Hospital's size and Governmental dependency of hospitals ${ }^{5}$. Hospital size was measured on the number of beds (Abernethy and Brownell, 1999; Errasti, 1997). Governmental dependency was measured dividing hospitals into two groups: The first group encloses the regions with a longer autonomy in health care management (e.g. Andalucía, Navarra, Canarias, Cataluña, Valencia, Galicia and País Vasco). The second group encloses the rest of Spanish regions, which have a recent autonomy in health care management (before 2002 these regions depended on a central service called Insalud).

\section{RESULTS}

Before testing our hypothesis, we analyzed for potential non-response bias involved comparing survey respondents to the original mailing list and comparing early and late respondents (cf. Pedhazur and Pedhazur, 1991) ${ }^{6}$. Chi-square tests and independent-samples t-tests on various characteristics, size of hospitals and governmental dependency, did not reveal any sign of non-response bias. Table 2 shows the descriptive statistics for the variables studied and the correlation matrix. The first hypothesis required a test of the expected positive relation between sophisticated AIS and prospector strategy. A zero-order correlation test confirmed this hypothesized relationship. Our expectation was supported as the correlation coefficient was positive and significant.

5 From 2002 the health care management is decentralized in Spain. Every region has autonomy and independence to manage health care institutions (included hospitals). In spite of this decentralized administration, it is likely that health care management does not differ significantly across regions. In this vein, there is a crossregional committee to monitor and balance health care services in the whole Spanish health care industry.

6 Quantitative data analysis was conducted using SPSS statistic software for Windows v. 11.0 


\begin{tabular}{|l|c|c|c|c|c|c|}
\hline & Mean & SD & $\begin{array}{c}\text { Theoretical } \\
\text { range }\end{array}$ & \multicolumn{2}{c|}{$\begin{array}{c}\text { Actual } \\
\text { range }\end{array}$} & \multicolumn{2}{|c|}{$\begin{array}{c}\text { Pearson correlation coefficients } \\
\text { (p-value) }\end{array}$} \\
\hline & & & & & Strategy & Performance \\
\hline AIS & 3.45 & 0.26 & $1.00-5.00$ & $1.63-3.94$ & $0.29(0.07)^{\mathrm{c}}$ & $0.18(0.08)^{\mathrm{c}}$ \\
\hline Strategy & 3.27 & 0.55 & $1.00-5.00$ & $1.00-5.00$ & ---- & $0.37(0.02)^{\mathrm{b}}$ \\
\hline Performance & 0.70 & 0.04 & $0.00-1.00$ & $0.47-0.93$ & ---- & --- \\
\hline
\end{tabular}

${ }^{\text {a }}$ Significant at 0.01 level (two tailed), ${ }^{\mathrm{b}}$ Significant at 0.05 level (two tailed), ${ }^{\mathrm{c}}$ Significant at 0.1 level (two tailed). Table 2 Descriptive statistics and correlation matrix. $\mathrm{N}=112$

For analyzing hypothesis 2 we used a path analysis (see Figure 1). As hypothesis 2 postulated an indirect effect of sophisticated AIS on performance acting through prospector strategy, the path model was the following:

$$
\begin{aligned}
& X_{2}=p_{11} X_{1}+\mu_{1} \\
& X_{3}=p_{21} X_{1}+p_{22} X_{2}+\mu_{2}
\end{aligned}
$$

Where:

$\mathrm{X}_{1}=$ Sophisticated AIS

$\mathrm{X}_{2}=$ Prospector Strategy

$\mathrm{X}_{3}=$ Organizational Performance

$\mathrm{p}_{11} \mathrm{p}_{21}$ and $\mathrm{p}_{22}=$ path coefficients explanatory variables

$\mu_{1}, \mu_{2}=$ error terms

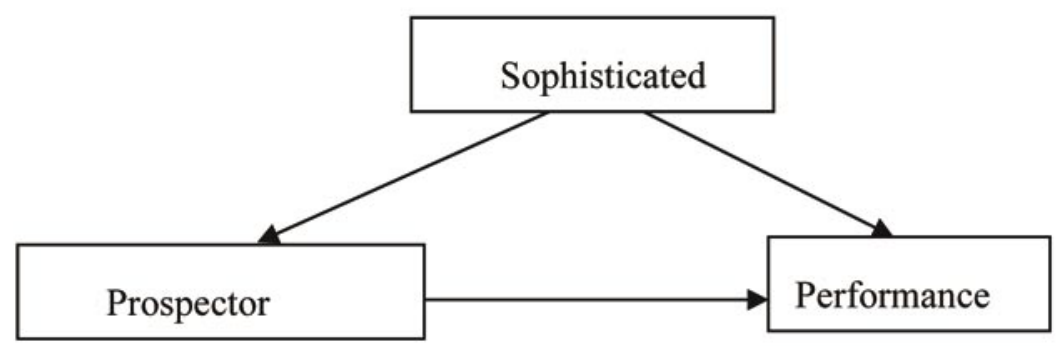

Figure 1: Path Analysis (Mediating Model)

The path coefficient of the relation between sophisticated AIS and prospector strategy is determined regressing $\mathrm{X}_{2}$ against $\mathrm{X}_{1}$, since it is assumed in the model that only sophisticated AIS determine prospector strategy. Path coefficients $\mathrm{p}_{21}$ and $\mathrm{p}_{22}$ are calculated by regressing performance on both sophisticated AIS and prospector strategy. Assuming residuals of the variables $\mathrm{X}_{2}$ and $\mathrm{X}_{3}$ are uncorrelated, all path coefficients can be calculated as standardized beta from regression equations. Table 3 shows a non-significant path coefficient on the direct relation between AIS and performance, after controlling for the effect of strategy. However, table 3 shows 
a strong relationship between strategy and performance. The decomposition of the results presented in table 4 , shows a positive and significant indirect effect between AIS and performance. These results, combined with the previous results of Hypothesis 1, provide supporting for Hypothesis 2, since it appears that the primary effect of AIS on performance is via strategy.

\begin{tabular}{|l|l|l|l|l|l|}
\hline $\begin{array}{l}\text { Path } \\
\text { coefficient }\end{array}$ & Linkage & Value & Standard error & $\mathrm{t}$ & $p$-value \\
\hline $\mathrm{p}_{11}$ & AIS/Strategy & 0.29 & 0.10 & 1.94 & 0.07 \\
\hline $\mathrm{p}_{21}$ & AIS/Performance & 0.11 & 0.08 & 1.52 & 0.13 \\
\hline $\mathrm{p}_{22}$ & Strategy/Performance & 0.35 & 0.12 & 2.71 & 0.04 \\
\hline
\end{tabular}

Table 3. Results of the path analysis

\begin{tabular}{|l|l|l|l|l|}
\hline Linkage & Direct & Indirect/spurious $^{\mathrm{a}}$ & Total $^{\mathrm{b}}$ & $p$-value \\
\hline AIS/Strategy & 0.29 & & 0.29 & 0.07 \\
\hline AIS/Performance & 0.11 & $\mathbf{0 . 0 7}$ & 0.18 & 0.08 \\
\hline Strategy/Performance & 0.35 & 0.02 & 0.37 & 0.02 \\
\hline
\end{tabular}

${ }^{\mathrm{a}}$ Indirect effects of AIS on performance (through strategy) are shown in bold prints. ${ }^{\mathrm{b}}$ Zero order correlation.

Table 4. Path analysis decomposition of effects

For testing Hypothesis 3 we used moderated regression analysis (see Figure 2), which is suitable to test the significance of the interaction effects between sophisticated AIS and prospector strategy (Hartmann and Moers, 1999). The moderated interaction relationship is modeled by including a product term as an additional independent variable (Hartmann and Moers, 1999). The following regression equation was tested:

$$
\mathrm{Y}=\beta_{0}+\beta_{1} \mathrm{X}_{1}+\beta_{2} \mathrm{X}_{2}+\beta_{3} \mathrm{X}_{1} \mathrm{X}_{2}+\mu
$$

where $\mathrm{Y}$ denotes organizational performance, $\mathrm{X}_{1}$ denotes AIS and $\mathrm{X}_{2}$ denotes strategy.

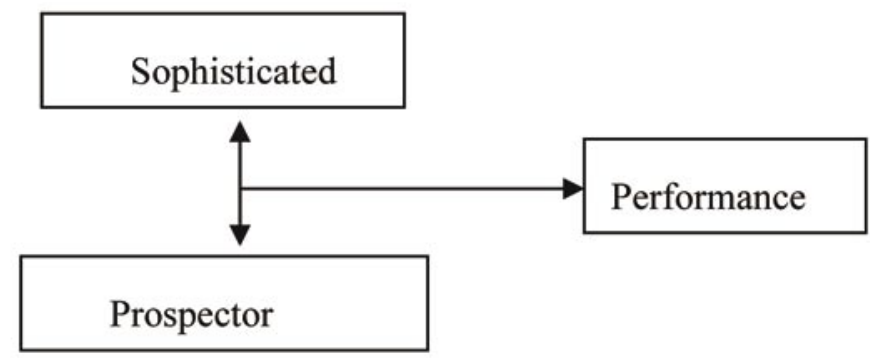

Figure 2: Interaction between AIS and Strategy on Performance 
The hypothesis 3 predicts that $\beta_{3}$ will be positive and significant. This can be examined by considering the following partial relation:

$$
\partial \mathrm{Y} / \partial \mathrm{X}_{1}=\beta_{1}+\beta_{3} \mathrm{X}_{2}
$$

If $\beta_{3}$ is positive, sophisticated AIS will have a progressively more positive effect on performance as the prospector strategy increases. Since the focus on interest is the contingency fit, only the regression coefficient $\beta_{3}$ is of interest (Govindarajan, 1986; Gul, 1991). Other variables in the model should be ignored as the variables are measured only on an interval scale (Govindarajan, 1986). Any relevant interaction term effect was determined not only analyzing the appropriated sign of the interaction term but also by evaluating the change in the explanatory power of the regression model. The test for this was to evaluate the significance of the adjusted $\mathrm{R}$ squared of the model which includes the interaction term, over the model which excludes it.

\begin{tabular}{|l|c|c|}
\hline \multicolumn{1}{|c|}{ VARIABLES } & $\begin{array}{c}\text { MAIN } \\
\text { EFFECTS } \\
\text { Coefficients (p-value) }\end{array}$ & $\begin{array}{c}\text { INTERACTION } \\
\text { EFFECT } \\
\text { Coefficients (p-value) }\end{array}$ \\
\hline Constant & $3.66(0.00)^{\mathrm{a}}$ & $5.09(0.00)^{\mathrm{a}}$ \\
Sophisticated AIS $\left(\beta_{1}\right)$ & $0.08(0.03)^{\mathrm{b}}$ & $0.12(0.08)^{\mathrm{c}}$ \\
Prospector Strategy $\left(\beta_{2}\right)$ & $0.13(0.02)^{\mathrm{b}}$ & $0.19(0.11)$ \\
Sophisticated AIS x Strategy $\left(\beta_{3}\right)$ & & $0.09(0.17)$ \\
& Adj. $\mathrm{R}^{2}=0.084$ & Adj. $\mathrm{R}^{2}=0.085$ \\
& $\mathrm{~F}=6.153^{\mathrm{a}}$ & $\mathrm{F}=6.802^{\mathrm{a}}$ \\
\hline
\end{tabular}

Dependent variable $=$ organizational performance. $\mathrm{N}=112$

${ }^{\mathrm{a}}$ Significant at 0.01 level (two tailed), ${ }^{\mathrm{b}}$ Significant at 0.05 level (two tailed), ${ }^{\mathrm{c}}$ Significant at 0.1 level (two tailed). Table 5. Results of moderated regression analysis.

The results in table 5 do not provide supporting for hypothesis 3 since the regression coefficient $\beta_{3}$ is positive but not significant. Then the interaction between sophisticated AIS and prospector strategy do not affect performance ${ }^{7}$. Even more, the results on table 5 show a weak significant increase in the explanatory power of the regression equation because of the inclusion of the interaction term. This does not provide evidence in favor of the argument that the change in performance as a result of change in strategy can be significantly better explained when sophisticated AIS design is introduced as a moderating factor. To add some intuitive appeal

7 The correlation between organizational performance and both size and governmental dependency were not significant, which suggests that size and governmental dependency were not confounding variables (Gul, 1991). 
and extend the results of the regression analyses we examined the relationship using a two-way ANOVA. Strategy was split on the basis of the median scores to create two groups: Prospector Strategy (above median) and Defender Strategy (below median). AIS design was also split at the median to create two groups: Sophisticated AIS (above median) and Traditional AIS (below median) ${ }^{8}$. The mean scores for performance shown in Table 6 indicate that performance is highest when high sophisticated AIS are matched with prospector strategy, but not when low sophisticated or traditional AIS are matched with defender strategy. Table 6 also shows that performance is lowest when high sophisticated AIS fit with defender strategy (mismatch). These results support partially hypothesis 3.

\begin{tabular}{|c|c|c|}
\hline & Prospector Strategy & Defender Strategy \\
\hline High Sophisticated AIS & 71.24 & 69.77 \\
\hline Traditional AIS (low sophisticated) & 70.52 & 70.01 \\
\hline
\end{tabular}

Table 6: ANOVA Results: Mean Performance Scores

\section{DISCUSSION AND CONCLUSIONS}

The objective of this paper was to empirically analyze the relationship between an organization's strategy and its AIS design. Specifically, this research has examined two related questions. Do firms design the AIS to enable their chosen strategy? If so, what are the resulting effects on performance? Regarding the relationship between AIS design and strategy the findings support our expectation that sophisticated AIS are positively related to prospector strategy. Regarding the effect on performance our findings provide support for the mediating model. That is, sophisticated AIS affect performance indirectly, through a prospector strategy. However the findings do not provide support for the moderating model, that is the interaction between sophisticated AIS and prospector strategy does not enhance performance. A plausible cause for this opposing result can be that strategy and AIS have to be analyzed as a group (not as continuum variables). The ANOVA analysis shows partial support for this cause, since performance is highest when a dominant strategy (e.g. prospector) is well matched with a dominant AIS design (e.g. sophisticated). The ANOVA analysis also shows that the performance is lowest when strategy is mismatched with AIS design (e.g. defender strategy and

8 Since ANOVA assumes equality of variance between groups, previously we checked the variance using the Levene test. The significance value of the Levene statistic was 0.157 (higher than 0.05 ), showing homogeneity of variance. 
sophisticated AIS). This is consistent with the central contention of the contingency approach which asserts that organizational components must fit each other or friction is created that prevents the firm from performing optimally (Donaldson, 2001; Chenhall, 2003).

Overall, our data suggest that AIS is a mechanism that enables organizational strategy and enhance performance. We can conclude that the more prospector the strategy the more the sophisticated AIS design. This is consistent with Bouwens and Abernethy (2000) and Abernethy and Lillis (1995), who argued that prospector strategies need sophisticated accounting systems in order to meet the uncertainty and market demand. Galbraith (1977) also pointed out that complexity in the environment is related to higher demand for information by managers. Abernethy and Lillis (1995) and Bouwens and Abernethy (2000) found a positive relationship between more comprehensive information (e.g. non-financial and operational) and a strategy focused on flexibility and customization respectively. Bouwens and Abernethy (2000) also found that customization does not have a direct relation with management accounting systems but rather operates indirectly via organizational interdependences. The mediating model between AIS, strategy and performance pointed out that managers recognize the importance of receiving more sophisticated information to manage more complex strategies in order to enhance the organizational performance. On the other hand, traditional or low sophisticated AIS are more suitable for enhancing the performance in defender organizations. In these organizations the uncertainty is very low or non-existent. Moreover the nature of the work is relatively stable with founded routines for performing tasks (Abernethy and Brownell, 1999). Thus traditional AIS prevent managers from information overload, which may be dysfunctional for translating strategy into specific objectives (Gul, 1991). As a consequence, traditional AIS facilitate the effective communication of strategic objectives and performance improvements in defender organizations.

This study has demonstrated that the AIS design can be more or less supportive in function of the business strategy employed by the organization. The results also support the more fundamental proposition in contingency theory, namely that in different contexts different internal factors will lead to high organizational performance. Moreover this paper provides empirical evidence from the public sector, extending prior research in the strategy and accounting information systems field that relied heavily on anecdotal evidence and limited sample sizes. 
This paper has several limitations, such as lack of ability to test for causal direction and the focus on a single industry. Causality cannot be assessed through cross sectional studies like this one (Pedhazur and Pedhazur, 1991). Relying on a single industry limited the generalizability of our findings. Although we believed that this sector is well suited to test our hypotheses, it may contain idiosyncrasies that have been overlooked. This study is exploratory in nature and leaves ample room for future research. Clearly, empirical testing of our hypotheses in a different industrial setting may provide insight into the external validity of the results. As only formal AIS were investigated future research can examine the role of informal information systems in the strategic change. Finally it can also be analyzed how the interrelation between strategy and informal information systems affects organizational performance.

\section{REFERENCES}

ABERNETHY, M.A.; GUTHRIE, C.H. (1994): "An empirical assessment of the "Fit" between strategy and management information system design", Accounting and Finance, 34, 2, 49-66.

ABERNETHY, M.A; BROWNELL, P. (1999): "The role of budgets in organizations facing strategic change: an exploratory study", Accounting, Organizations and Society, 24, 189-204.

ABERNETHY, M.A.; LILLIS, A.M. (1995): "The impact of Manufacturing Flexibility on Management Controls System Design", Accounting, Organizations and Society, 20, 4, 241-258.

ABERNETHY, M.A.; VAGNONI, (2004): "Power, organization design and managerial behaviour", Accounting, Organizations and Society, 29, 207-225.

BARUA, A.; KRIEBEL, C.H.; MUKHOPOADHYAY, T. (1995): "Information Technologies and Business Value: An Analytic and Empirical Investigation", Information Systems Research, 6,1, 3-23.

BERGERON, F.; RAYMOND, L.; RIVARD, S. (2001): "Fit in strategic information technology management research: an empirical comparison of perspectives", Omega, 29, 125-142. 
BOUWENS, J.; ABERNETHY, M.A. (2000): “The consequences of customization on management accounting systems design", Accounting, Organizations and Society, 25,3, 221-259.

BROWN, C.V.; MAGILL, S.L. (1994): "Alignment of the IS functions with the enterprise: toward a model of antecedents", MIS Quarterly, 18, 4, 371-403.

CARRETERO ALCÁNTARA, L. (2000): "Herramientas para la Gestión Clínica", Gestión Hospitalaria, 11, 15-21.

CHAPMAN, C.S. (1997): "Reflections on a contingent view of accounting", Accounting, Organizations and Society, 22, 189-205.

CHENHALL, R.H.; MORRIS, D. (1986): "The impact of Structure, Environment, and Interdependence on the Perceived Usefulness of Management Accounting Systems", The Accounting Review, 61, 16-35.

CHENHALL, R.H. (2003): "Management control systems design within its organizational context: findings from contingency-based research and directions for the future", Accounting, Organizations and Society, 28, 2-3, 127-168.

DONALDSON, L. (2001): The contingency theory of organizations, Ed. Sage, California.

DRAZIN, R.; VAN DE VEN, A.H. (1985): “Alternative forms of fit in contingency theory", Administrative Science Quarterly, 30, 514-539.

ERRASTI, F. (1997): Principios de Gestión Sanitaria, Diaz de Santos S.A., Madrid

FIEGENER, M.K. (1994): "Matching Business-Level Strategic Controls to Strategy: Impact on Control System Effectiveness", Journal of Applied Business Research, 10, 1, 25-34.

GALBRAITH, J.R. (1977): Organization Design, Reading, Massachusetts: Addison-Wesley.

GERDIN, J.; GREVE, J. (2004): "Forms of contingency fit in management accounting research-a critical review", Accounting, Organizations and Society, 29, 3-4, 303-326. 
GOLDEN, B.R. (1992): "SBU Strategy and Performance: The Moderating Effects of the Corporate-SBU Relationship", Strategic Management Journal, 13, 2, 145158.

GORDON, L.; MILLER, D.A. (1976): "Contingency Framework for the Design of Accounting Information Systems"; Accounting, Organizations and Society, 1, 1, 59-69.

GOVINDARAJAN, V. (1986): "Impact of Participation in the Budgetary Process on Managerial Attitude and Performance: Universalistic and Contingency Perspectives"; Decision Sciences, 17, 4, 496-516.

GUL, F.A. (1991): "The effects of Management Accounting Systems and Environmental Uncertainty on Small Business Managers' Performance", Accounting and Business Research, 22, 85, 57-61.

GUL, F.A.; CHIA, Y.M. (1994): "The effects of management accounting systems, perceived environmental uncertainty and decentralization on managerial performance: A test of three way interaction", Accounting, Organizations and Society, 19, 4/5, 413-426.

HARTMANN, F.G.H.; MOERS, F. (1999): "Testing contingency hypotheses in budgetary research: an evaluation of the use of moderated regression analysis", Accounting, Organizations and Society, 24, 291-315.

ITTNER, C.D.; LARCKER, D.F. (1997): "Quality Strategy, Strategic Control Systems, and Organizational Performance", Accounting, Organizations and Society, 22, 3/4, 293-314.

JOHNSON, H.T.; KAPLAN, R.S. (1987): Relevance Lost: The Rise and Fall of Management Accounting, Harvard Business School Press, Boston.

KALD, M., NILSSON, F.; RAPP, B. (2000): “On strategy and management control: the importance of classifying the strategy of the business"; British Journal of Management; 11, 197-212.

LANGFIELD-SMITH, K. (1997): "Management Control Systems and Strategy: A critical Review", Accounting, Organizations and Society, 22, 2, 207-232. 
LAWRENCE, B.C.; LORSCH, J.W. (1967): Organization and Environment. Boston: Harvard Business School Press.

MILES, R.E.; SNOW, C.C. (1978): Organizational Strategy, Structure, and Process; McGraw-Hill Book Company, New York.

NUNNALLY, J.D. (1978): Psychometric theory; $2^{\mathrm{a}}$ ed. New York, McGraw-Hill

OTLEY, D.T. (1980): "The contingency theory of management accounting achievement and prognosis"; Accounting, Organizations and Society, 5, 4, 413428.

PEDHAZUR, E.J.; PEDHAZUR, L. (1991): Measurement, Design and Analysis: An Integrated Approach, Lawrence Erlbaum Associates, United States.

PERERA, S.; HARRISON, G.; POOLE, M. (1997): “Customer-focused manufacturing strategy and the use of operation-based non-financial performance measures: a research note", Accounting, Organizations and Society, 22, 6, 557572 .

PORTER, M.E. (1985): Competitive Advantage: Creating and Sustaining Superior Performance, The Free Press, New York.

SHORTELL, S.M.; ZAJAC, E. (1990): "Perceptual and archival measures of Miles and Snow's strategic types: A comprehensive assessment of reliability and validity", Academy of Management Journal, 33, 817-832.

SIMONS, R. (1995): Levers of Control: How Managers Use Innovative Control Systems to Drive Strategic Renewal, Boston, Ma: Harvard Business School Press.

SNOW, C.C.; HREBINIAK, L.G. (1980): "Strategy, distinctive competence and organizational performance", Administrative Science Quarterly, 25, 317-336.

VAN PEURSEM, K.A., PRATT, M.J.; LAWRENCE, S.R. (1995): "Health management performance: A review of measures and indicators", Accounting, Auditing \& Accountability, 8, 5, 34-70. 
VENKATRAMAN, N. (1989): "The concept of fit in strategy research: Toward verbal and statistical correspondence", Academy of Management Review, 14, 3, 423-444.

ZAHRA, S.A.; PEARCE, J.A. (1990): "Research Evidence on the Miles-Snow Typology", Journal of Management, 16, 751-768.

\section{APPENDIX: Questionnaire}

\section{AIS Design}

CEOs were asked to indicate the extent to which they perceived that their AIS provided each of the following characteristics:

- Past-oriented Information

- Future-oriented information

- Internal information (events inside organization)

- External information

- Economic information (quantified in monetary terms)

- Non-economic information (quantified in non-monetary terms)

- Long-run oriented information

- Short-run oriented information

- Reports aggregated information (e.g. by sections, functional areas, time)

- Report precise information (e.g. precise target for activities/services)

- Timeliness of information reporting (e.g. for managing, decision making)

- Report coordinated information by sections/functional areas

\section{Strategy}

The following two descriptions were given to CEOs. They were asked to place their hospital along a five-point scale bounded by a " 1 " (Hospital A=Defender) to a "5" (Hospital B=Prospector).

"Hospital A offers a relatively stable set of services and tends to focus on a particular segment of the population an offers a more limited range of services 
that other hospitals of the same categories. Generally Hospital A is not at the forefront of new services developments in health care. Developments in services tend to concentrate on current areas of operation. It believes that doing the best job possible in its existing range of services and refining existing services are of utmost importance."

"Hospital B makes relatively frequent changes in, and additions to, its set of services and tends to offer a wider range of medical services compared to other hospitals of the same categories. Hospital B responds rapidly to early signals of market needs or opportunities and it consistently attempts to be at the forefront of new service developments. Other hospitals often follow Hospital B in the development of these services. This type of hospital may not maintain its strength in all of the areas it enters." 